\title{
Demographic characteristics of veterans who received wheelchairs and scooters from Veterans Health Administration
}

\author{
Sandra L. Hubbard, PhD, OTR/L, ATP; ${ }^{1-2}$ Shirley G. Fitzgerald, PhD; ${ }^{3-4 *}$ Dean M. Reker, PhD, RN; ${ }^{5-6}$ \\ Michael L. Boninger, MD; ${ }^{4,7}$ Rory A. Cooper, PhD; ${ }^{3-4}$ Lewis E. Kazis, ScD ${ }^{8-9}$ \\ ${ }^{1}$ Department of Veterans Affairs (VA) Rehabilitation Outcomes Research Center of Excellence, North Florida/South \\ Georgia Veterans Health System, Gainesville, FL; ${ }^{2}$ Department of Occupational Therapy, University of Florida, \\ Gainesville, FL; ${ }^{3}$ Department of Rehabilitation Sciences and Technology, University of Pittsburgh, Pittsburgh, PA; \\ ${ }^{4}$ Human Engineering Research Laboratories, VA Pittsburgh Healthcare System, Pittsburgh, PA; ${ }^{5}$ Kansas City VA Medi- \\ cal Center, Kansas City, MO; ${ }^{6}$ Department of Health Policy and Management, The University of Kansas Medical Cen- \\ ter, Kansas City, KS; ${ }^{7}$ Department of Physical Medicine and Rehabilitation, University of Pittsburgh, Pittsburgh, PA; \\ ${ }^{8}$ Department of Health Policy and Management, Boston University School of Public Health, Boston, MA; ${ }^{9}$ VA Center \\ for Health Quality, Outcomes, and Economic Research, Bedford, MA
}

\begin{abstract}
Little is known about the reasoning process clinicians use when prescribing wheeled mobility equipment (WME) or about the outcomes of this process, i.e., how many devices are prescribed, to whom, how often, and at what cost. This study characterized veterans who received WME from the Veterans Health Administration. We analyzed variance in wheelchair provision based on sex, race/ethnicity, diagnosis, and age. Three years of data from the National Prosthetics Patient Database and the National Patient Care Database were merged, yielding more than 77,000 observations per fiscal year. Logistic regression analysis revealed associations between WME provision and age, sex, and race/ethnicity, when analysis was controlled for diagnosis and number of comorbidities. Hispanics (odds ratio [OR] = 1.864), African Americans $(\mathrm{OR}=1.360)$, and American Indians/Asians $(\mathrm{OR}=$ 1.585) were more likely than Caucasians to receive standard wheelchairs. Hispanics $(\mathrm{OR}=0.4)$, African Americans $(\mathrm{OR}=$ $0.7)$, and American Indians/Asians (OR $=0.4$ ) were less likely than Caucasians to receive scooters.
\end{abstract}

Key words: age, assistive technology, equity, ethnicity, power wheelchair, race, rehabilitation, sex, standard manual wheelchair, wheeled mobility equipment.

\section{INTRODUCTION}

Little is known about the decision process in which clinicians engage when prescribing wheeled mobility

Abbreviations: ALS = amyotrophic lateral sclerosis, ATD = assistive technology device, ATS = assistive technology specialist, $\mathrm{COPD} / \mathrm{CHF}=$ chronic obstructive pulmonary disorder/ chronic heart failure, $\mathrm{CV}$ = confounding variable, $\mathrm{DV}=$ dependent variable, FY = fiscal year, HCPCS = Healthcare Common Procedure Coding System, ICD-9 = International Classification of Diseases-Revision 9, IV = independent variable, MS = multiple sclerosis, NPCD = National Patient Care Database, NPPD = National Prosthetics Patient Database, NSC/OP = non-service-connected and outpatient, $\mathrm{OR}=$ odds ratio, $\mathrm{PD}=$ Parkinson's disease, SCI = spinal cord injury, SCIP = SCIparaplegia, SCIT = SCI-tetraplegia, SC/OP = service-connected and outpatient, $\mathrm{SD}=$ standard deviation, $\mathrm{TBI}=$ traumatic brain injury, VA = Department of Veterans Affairs, VHA = Veterans Health Administration, VHS = Veterans Health Study, WME = wheeled mobility equipment.

* Address all correspondence to Shirley G. Fitzgerald, PhD; Human Engineering Research Laboratories (151R-1), VA Pittsburgh Healthcare System, 7180 Highland Dr, Pittsburgh, PA 15206; 412-365-4850; fax: 412-365-4858. Email: sgf9@pitt.edu DOI: 10.1682/JRRD.2005.11.0174 
equipment (WME), i.e., wheelchair or scooter. Equally unknown are the outcomes of this decision process, i.e., how many devices are being prescribed, to whom, how often, and at what cost. Demographic variance has been found in several studies of assistive technology device (ATD) provision, including wheelchairs, in the nonveteran population [1-4]. One study described demographic variance in wheelchair provision for individuals with spinal cord injury (SCI) in the general population [5]. No known studies have addressed wheelchair provision within the veteran population.

Using National Health Interview Survey on Disability data, Kaye et al. found more women (58.8\%) use WME than men and wheelchair use was highest for Native Americans (0.81\%), followed by Caucasians (0.63\%), African Americans (0.56\%), and Hispanics (0.36\%) [3]. Two studies found no significant difference in WME use between African-American and Caucasian older populations [2,4]. Using Canadian Aging Research Network data, Zimmer and Chappell found rural older people (mean age $=78$ ) with more chronic conditions and more mobility difficulties tended to use ATDs more often [6]. Each year of age increased the chance of ATD use by 1.04. Each chronic condition increased the chance of ATD use by 1.18 , and each additional mobility problem increased the chance of ATD use by 2.47. Tomita et al.'s study counted devices owned [4], while Zimmer and Chappell's study counted the tasks for which devices were used [6].

Typically, studies investigating demographic differences of individuals who receive and/or use ATDs consider all wheelchairs as one category of assistive technology and thus assume all wheelchairs are created equal $[2,4,7]$. To the contrary, wheelchairs span the technological spectrum [8], from "depot” manual wheelchairs with standard sling upholstery, chrome-plated steel, and a folding X-frame design to power wheelchairs with tilt, recline, and seat elevation options and programmable electronic controls that can be individualized for abnormal muscle tone, tremor, and cognitive impairment [9].

Substantial improvements in WME offer consumers more and better choices [10-14]. However, as the technology becomes more complex, so do the decisions as to who gets which wheelchair, with both cost and clinical expertise as factors. Clinicians making these decisions may not have training in WME options and features and thus may have difficulty comprehending the complexity of the technology and its application [15-19].
This study characterized veterans who received WME from the Veterans Health Administration (VHA) and determined whether characteristics varied significantly according to the type of WME provided. Our hypothesis was that the type of wheelchair provided to veterans would differ significantly according to age, sex, and race/ethnicity for fiscal years (FYs) 1999-2001 combined.

\section{METHODS}

\section{Design and Participants}

Using a cross-sectional, retrospective study design, we merged 3 years of data from two VHA databases, the National Prosthetics Patient Database (NPPD) and the National Patient Care Database (NPCD), to create a data set of demographic and clinical information on veterans who received WME from the VHA during FYs 19992001.

\section{Databases}

\section{National Prosthetics Patient Database}

The NPPD, which is housed at the Department of Veterans Affairs (VA) Central Offices [20-21], contains detailed information on the procurement of prosthetic, orthotic, and sensory technology by tracking every device issued to veterans by the VHA. Of the 25 data fields included in the NPPD, 7 were used in this study: device code, device description, service type (initial issue, replacement, or spare), creation date, delivery date, service category, and priority group.

\section{National Patient Care Database}

We used the NPCD, which is housed at the VA Austin Automation Center, to create SAS ${ }^{\circledR}$ (SAS Institute, Inc, Cary, North Carolina) data sets that contained VHA outpatient and inpatient healthcare data. The NPCD data fields used in this study included date of birth, sex, race, and primary and secondary International Classification of Diseases-Revision 9 (ICD-9) codes [22]. We used data from both the inpatient and outpatient databases to decrease the number of missing values. For example, if sex was missing in the inpatient data set, it was retrieved from the outpatient data set. 


\section{Operational Definitions of Variables}

Dependent Variable: Type of Wheelchair

Because of the large number of unique wheelchairrelated Healthcare Common Procedure Coding System (HCPCS) codes included in the NPPD $(n=71)$, analysis of each wheelchair code was not feasible; therefore, for the purpose of this study, the HCPCS codes used in the NPPD were assigned to one of eight types based on function, weight, and adjustability. See Table 1 for assigned wheelchair types by HCPCS code.

\section{Independent Variables}

Age. We calculated veteran age by subtracting the date of birth from the day on which the wheelchair order was entered into the NPPD (VHA policy specifies the device must be entered within 5 days of prescription).

Race/Ethnicity. Race/ethnicity was initially defined according to the six NPCD race categories: Hispanic black, Hispanic white, American Indian, African American, Asian, and Caucasian. However, because of inadequate cell size, we combined Hispanic black with Hispanic white and American Indian with Asian.

\section{Confounding Variables}

Diagnoses. ICD-9 codes from the primary diagnoses variables for all FY1999-2001 encounters were extracted from the inpatient and outpatient NPCD data sets. Participants were then assigned one diagnosis most related to their wheelchair use, which resulted in the following categories: amyotrophic lateral sclerosis (ALS), multiple sclerosis (MS), SCI-tetraplegia (SCIT), SCI-paraplegia (SCIP), stroke, traumatic brain injury (TBI), Parkinson's disease (PD), amputation, chronic obstructive pulmonary disorder/chronic heart failure (COPD/CHF), arthritis, and "other." We used the "other" category only when creating the data set to provide an idea of the proportion of veterans who did not receive WME for the 10 main diagnostic categories. However, the "other" category was not included in the analyses since it would not yield useful information.

Comorbidities. To determine the number of comorbidities, we extracted the ICD-9 codes that represented secondary diagnoses from the FY1999-2001 inpatient and outpatient NPCD data sets. The ICD-9 codes were sorted into the 30 medical categories (anemia, CHF, diabetes, stroke, etc.) developed for the Veterans Health Study

Table 1.

Operational definitions of dependent variable, wheelchair type. Devices identified in National Prosthetics Patient Database by Healthcare Common Procedure Coding System (HCPCS) codes were assigned one of eight types according to function, weight, and adjustability.

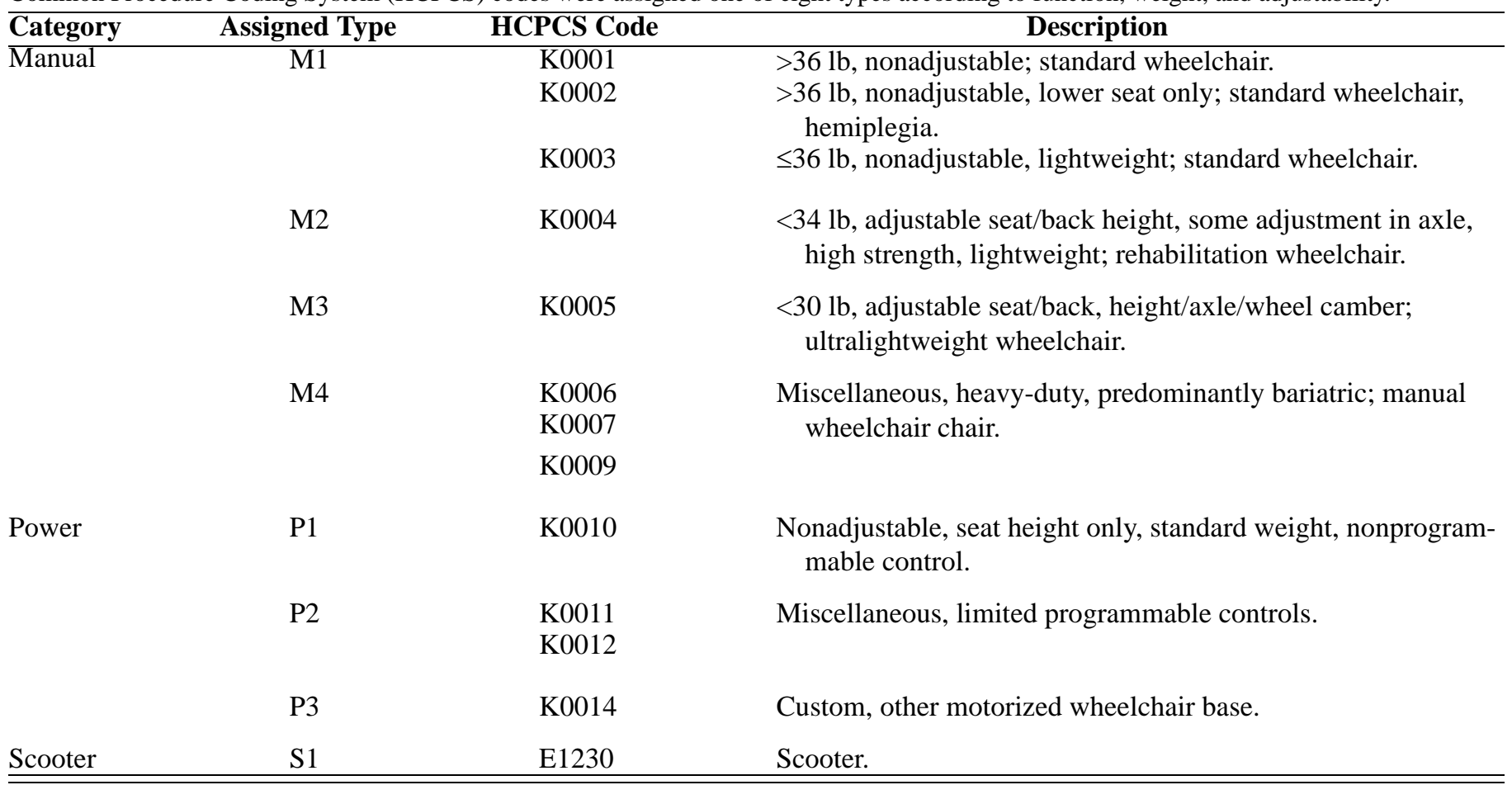


(VHS) [23-24]. A continuous variable was created that represented the number of comorbidities. If a veteran had a primary diagnosis that was also one of the 30 medical categories, the comorbidity count was adjusted; i.e., if the veteran's primary diagnosis was stroke, the comorbidity count was reduced by one, since stroke was also one of the 30 medical categories developed for the VHS.

\section{Other Variables Included in Descriptive Analyses}

Service type designated whether the device was the first the veteran had received from the VHA, a spare, or a replacement. Four service categories were detailed: service-connected and inpatient, service-connected and outpatient (SC/OP), non-service-connected and inpatient, and non-service-connected and outpatient (NSC/OP). Categories were assigned for each device provided; for example, a veteran could have one wheelchair that was SC/OP and a scooter that was NSC/OP. Priority groups [25] ranged from Group 1, veterans with disabilities rated $\geq 50$ percent service-connected, to Group 7, high-income veterans with disabilities rated 0 percent service-connected or non-service-connected.

\section{Data Cleaning}

We applied procedures for data cleaning that were developed during a collaborative validity study of the NPPD [21]. For example, a comparison of the frequency counts of the records contained in the "NPPD_Line" and "HCPCSPSAS" fields determined that the "NPPD_Line" field was the most reliable and valid method of selecting the wheelchair and scooter items. When inconsistencies between these fields were found, we considered other fields including vendor, cost, and item description and recoded the record accordingly. For all three FYs, only three devices required recoding: a scooter and two manual wheelchairs. No algorithms for altering the data were applied.

Miscoding of SCIT and SCIP was noted; for example, a veteran could be SCIT in one encounter and SCIP in another. Since this miscoding would affect the validity of the results (i.e., it does not make sense for an individual with high-level SCIT to receive a manual wheelchair), the two categories were combined for analyses.

\section{ANALYSES}

We used descriptive methods (frequency, mean, standard deviation [SD], and median for skewed data) to characterize veterans who received WME from the VHA. Because an extensive research study with NPPD data was not found and FY1999 was the first year the NPPD was available to researchers, data were analyzed separately for each of the three FYs.

To determine which demographic variables to enter into the two logistic regression models, we performed analysis of variance and chi-square univariate analyses ( $\alpha=0.10$ ) between the independent variables (IVs), potential confounding variables (CVs), and the dependent variable (DV) - type of wheelchair. All IVs and CVs were significant; thus, age, sex, race/ethnicity, diagnosis, number of comorbidities, and FY were entered into both logistic regression models. Dummy variables were created for race/ethnicity, diagnosis (ALS, SCIP, SCIT, $\mathrm{PD}$, MS, stroke, TBI, amputation, COPD/CHF, and arthritis), and FY. Age and number of comorbidities were continuous variables.

The DV for the first logistic regression model was wheelchair type with all manual and power wheelchairs and scooters included; the DV for the second logistic regression model was wheelchair type with only power mobility devices (power wheelchairs and scooters) included. Both logistic regression models were tested at $\alpha=0.05$. Odds ratios (ORs), Wald confidence intervals, and $p$-values were reported [26-27].

\section{RESULTS}

\section{Descriptive Statistics}

The number of veterans who received wheelchairs and scooters ranged from 52,309 in FY1999 to 59,877 in FY2001, a 14 percent increase (Table 2). In contrast, the number of wheelchairs, scooters, or related wheelchair components provided to veterans was 77,249 in FY1999, 80,753 in FY2000, and 85,156 in FY2001 (data not shown). These numbers are higher because not all veteran WME users acquired a wheelchair or scooter during the study years; some only acquired an accessory, such as a new seating system. In addition, some veterans received more than one wheelchair during a FY. Approximately 70 percent of the WME provided during FYs 1999-2001 was either a wheelchair or a scooter; the remaining 30 percent fell into the category of wheelchairrelated accessories, i.e., cup holder, oxygen holder, gloves, or seating system not associated with a wheelchair purchase. 
Table 2.

Number of veterans who received devices from Veterans Health Administration during fiscal years (FYs) 1999-2001 as well as percent change from FY1999 to FY2001 by sex, race/ethnicity, diagnosis, and age.

\begin{tabular}{|c|c|c|c|c|}
\hline Variable & FY1999 (n) & FY2000 (n) & FY2001 (n) & Change (\%) \\
\hline Unique Veterans & 52,309 & 55,752 & 59,877 & 14 \\
\hline Male & 43,783 & 52,305 & 56,503 & 29 \\
\hline Missing & 6,854 & 1,513 & 1,188 & NA \\
\hline \multicolumn{5}{|l|}{ Race/Ethnicity } \\
\hline Hispanic, Black & 2,180 & 2,961 & 3,157 & 45 \\
\hline American Indian & 210 & 233 & 220 & 5 \\
\hline African American & 6,749 & 7,724 & 7,905 & 17 \\
\hline Asian & 143 & 164 & 228 & 59 \\
\hline Caucasian & 30,091 & 34,916 & 36,710 & 22 \\
\hline Unknown & 5,972 & 8,054 & 10,261 & NA \\
\hline Missing & 6,854 & 1,513 & 1,188 & NA \\
\hline SCIT/SCIP & 3,692 & 3,781 & 3,932 & 7 \\
\hline Stroke & 7,645 & 8,688 & 8,619 & 13 \\
\hline TBI & 56 & 58 & 48 & -14 \\
\hline $\mathrm{PD}$ & 1,199 & 1,575 & 1,835 & 53 \\
\hline Amputation & 2,106 & 2,323 & 2,176 & 3 \\
\hline COPD/CHF & 10,245 & 12,191 & 13,035 & 27 \\
\hline Arthritis & 5,059 & 6,180 & 7,033 & 39 \\
\hline Other & 13,227 & 16,953 & 19,297 & NA \\
\hline Missing & 6,988 & 1,596 & 1,413 & NA \\
\hline Age, yr (Mean \pm SD) & $66.6 \pm 13.1$ & $67.4 \pm 13.1$ & $67.8 \pm 13.0$ & 2 \\
\hline Missing & 6,854 & 1,513 & 1,188 & NA \\
\hline
\end{tabular}

Note: No demographic data for 15\% of veterans for FY1999, 3\% for FY2000, and 2\% for FY2001.

ALS = amyotrophic lateral sclerosis, COPD/CHF = chronic obstructive pulmonary disorder/chronic heart failure, MS = multiple sclerosis, NA = not applicable, PD = Parkinson's disease, SCIT/SCIP = spinal cord injury-tetraplegia/SCI-paraplegia, SD = standard deviation, TBI = traumatic brain injury .

Table 2 also displays the change in the number of veterans who received WME per demographic/clinical category (age, sex, race/ethnicity, diagnosis). COPD/ CHF (23\%) was the most frequent primary diagnosis of veterans who received WME followed by stroke (16\%), arthritis (11\%), SCIP and SCIT inclusive (7\%), amputation (4\%), PD (3\%), MS (3\%), ALS (1\%), and TBI $(<1 \%)$ (percentages not shown). The percentage of missing values for demographic data obtained from the NPCD (Table 2) was 15 percent for FY1999 and 2 to 3 percent for FYs 2000 and 2001. This is most likely because FY1999 was the first year the NPPD was available to researchers following its creation on October 1, 1997; the database may have had incorrect or improperly scrambled Social Security numbers.
Table 3 displays the types of WME provided by the VHA. Approximately 80 percent of the wheelchairs provided in FY1999 were manual, with a decrease to 77 percent in FY2001. The proportion of power wheelchairs increased from 8 percent in FY1999 and FY2000 to 14 percent in FY2001, while the proportion of scooters decreased from 13 percent in FY1999 and FY2000 to 9 percent in FY2001. The number of power wheelchairs increased by more than 100 percent between FY1999 and FY2001.

According to preliminary univariate analyses, more variance in the type of wheelchair provided was noted between Hispanics and Caucasians than between African Americans and Caucasians (Table 4). When all WME was compared (Table 4, first seven rows), Hispanics received higher percentages of standard and ultralightweight 
Table 3.

Number and percentage of devices provided by Veterans Health Administration during fiscal years (FYs) 1999-2001.

\begin{tabular}{|c|c|c|c|c|c|c|}
\hline \multirow{3}{*}{ FY } & \multicolumn{4}{|c|}{ Wheelchair } & & \\
\hline & \multicolumn{2}{|c|}{ Manual } & \multicolumn{2}{|c|}{ Power } & \multicolumn{2}{|c|}{ Scooter } \\
\hline & No. & $\%$ & No. & $\%$ & No. & $\%$ \\
\hline 1999 & 48,433 & 80 & 4,664 & 8 & 7,015 & 13 \\
\hline 2000 & 49,898 & 79 & 5,309 & 8 & 8,144 & 13 \\
\hline 2001 & 52,223 & 77 & 9,451 & 14 & 6,187 & 9 \\
\hline
\end{tabular}

wheelchairs (types M1 and M3) and lower percentages of standard power wheelchairs (type P1) and scooters than other racial/ethnic categories. All three minority categories received a higher percentage of standard wheelchairs (type M1) than Caucasians. Caucasians received a higher proportion of scooters than minorities.

When the proportion of manual and power wheelchairs and scooters per racial/ethnic group was compared (Table 4, last three rows), 90 percent of the WME types received by Hispanics were manual wheelchairs, 5 percent were power wheelchairs, and 5 percent were scooters. In contrast, 77 percent of the WME types received by Caucasians were manual wheelchairs, 9 percent were power wheelchairs, and 14 percent were scooters. The percentages for African Americans were in between those for Hispanics and Caucasians: 82 percent received manual wheelchairs, 8 percent power wheelchairs, and 10 percent scooters. With the exception of standard wheelchairs (type M1) and scooters, relatively little vari- ance was noted in the types of wheelchairs received by African Americans compared with Caucasians.

The average age of veterans who received ultralightweight manual and custom power wheelchairs (types M3 and P3) was $55.2 \pm 15.8$ and $59.9 \pm 13.9$, respectively, compared with the average age of veterans who received standard and lightweight rehabilitation wheelchairs (types M1 and M2) and scooters: $67.0 \pm 13.1,65.5 \pm$ 13.9, and $65.5 \pm 11.6$, respectively (Table 5). Age was normally distributed for all wheelchairs types. Data are presented as mean \pm SD unless otherwise noted.

The most frequently prescribed wheelchair for all diagnoses was the standard manual wheelchair (type M1). Table 6 shows the significant relationship between diagnosis and type of WME provided by displaying the distribution of each type of WME for each diagnosis. For example, 60 percent of veterans with ALS received manual and 40 percent received power wheelchairs (scooters were included in the power category). Further, 37 percent of the WME types received by veterans with ALS were standard manual wheelchairs, 13 percent were lightweight manual rehabilitation wheelchairs, 16 percent were scooters, and 6 percent were custom power wheelchairs (type P3).

The second most frequently prescribed wheelchair type varied by diagnosis: lightweight rehabilitation wheelchairs (type M2) for veterans with MS, SCIP/SCIT, stroke, TBI, PD, and amputation and scooters for veterans with ALS, COPF/CHF, and arthritis. Power devices,

Table 4.

Distribution (frequency and percent) of wheelchairs by type (manual/power wheelchairs and scooters) across racial/ethnic groups for fiscal years 1999-2001 combined.

\begin{tabular}{|c|c|c|c|c|c|c|c|c|c|c|}
\hline \multirow{3}{*}{$\begin{array}{l}\text { Dependent Variable: } \\
\text { Wheelchair Type }\end{array}$} & \multicolumn{8}{|c|}{ Independent Variable: Race/Ethnicity } & & \\
\hline & \multicolumn{2}{|c|}{ Hispanic } & \multicolumn{2}{|c|}{$\begin{array}{c}\text { American } \\
\text { Indian/Asian }\end{array}$} & \multicolumn{2}{|c|}{$\begin{array}{c}\text { African } \\
\text { American }\end{array}$} & \multicolumn{2}{|c|}{ Caucasian } & \multicolumn{2}{|c|}{ Total Devices } \\
\hline & No. & $\%$ & No. & $\%$ & No. & $\%$ & No. & $\%$ & No. & $\%$ \\
\hline M1 & 6,677 & 68 & 861 & 63 & 14,599 & 57 & 60,216 & 52 & 82,353 & 53 \\
\hline M2 & 1,461 & 15 & 192 & 14 & 3,779 & 15 & 18,590 & 16 & 24,022 & 16 \\
\hline M3 & 435 & 4 & 39 & 3 & 734 & 3 & 2,758 & 3 & 3,966 & 3 \\
\hline P2 & 141 & 1 & 39 & 3 & 704 & 3 & 3,354 & 3 & 4,238 & 3 \\
\hline P3 & 171 & 2 & 23 & 2 & 587 & 2 & 2,561 & 2 & 3,342 & 2 \\
\hline Total Manual & 8,810 & 90 & 1,150 & 84 & 21,015 & 82 & 89,647 & 77 & 120,622 & 79 \\
\hline Total Power & 511 & 5 & 109 & 8 & 2,173 & 8 & 10,177 & 9 & 12,970 & 8 \\
\hline Total Scooter & 522 & 5 & 104 & 8 & 2,454 & 10 & 16,248 & 14 & 19,328 & 13 \\
\hline
\end{tabular}


Table 5.

Distribution (frequency) of wheelchairs by type (manual/power wheelchairs and scooters) across age groups (mean \pm standard deviation [SD]) for fiscal years 1999-2001 combined.

\begin{tabular}{crc}
\hline $\begin{array}{c}\text { Dependent Variable: } \\
\text { Wheelchair Type }\end{array}$ & No. & $\begin{array}{c}\text { Age Group } \\
\text { (Mean } \pm \text { SD) }\end{array}$ \\
\hline M1 & 33,053 & $67.0 \pm 13.1$ \\
M2 & 9,749 & $65.5 \pm 13.9$ \\
M3 & 1,835 & $55.2 \pm 15.8$ \\
M4 & 4,732 & $62.5 \pm 13.9$ \\
P1 & 3,025 & $62.0 \pm 13.6$ \\
P2 & 1,838 & $62.7 \pm 13.5$ \\
P3 & 1,670 & $59.9 \pm 13.9$ \\
\hline Total Manual & 49,369 & $65.8 \pm 13.7$ \\
Total Power & 6,533 & $61.7 \pm 13.7$ \\
Total Scooter & 8,787 & $65.5 \pm 11.6$ \\
\hline \hline
\end{tabular}

i.e., power wheelchairs and scooters, were prescribed more often for veterans with ALS, MS, and SCIT ( 40\%) than for veterans with SCIP, stroke, TBI, PD, amputation, COPD/CHF, and arthritis ( $<30 \%)$.

For mean number of comorbidities per type of wheelchair (data not shown), veterans prescribed ultralightweight wheelchairs (type M3) had the least number of comorbidities: $2.3 \pm 2.1$. The mean number of comorbidities was $3.0 \pm 2.2$ for manual wheelchair users, $2.9 \pm 2.4$ for power wheelchair users, and $3.2 \pm 2.3$ for scooter users.

\section{Logistic Regression}

Tables 7 and 8 display the likelihood that veterans receive a certain type of wheelchair if they are older ver- sus younger, male versus female, and Hispanic versus Caucasian, American Indian/Asian versus Caucasian, or African American versus Caucasian. The results displayed in Table 7 were derived from a data subset that included manual and power wheelchairs only. The results displayed in Table 8 include power wheelchairs and scooters only.

Age

When all WME was compared, younger veterans were more likely to receive custom power wheelchairs (type P3) $(p=0.027)$ and scooters $(p \leq 0.001)$, whereas older veterans were more likely to receive manual wheelchairs $(p \leq 0.001)$. When only manual wheelchairs were compared (data not shown), older veterans were more likely to receive standard wheelchairs (type M1) $(p \leq$ 0.001 ), while younger veterans were more likely to receive ultralightweight wheelchairs (type M3) $(p \leq 0.001)$.

According to adjusted ORs (when all WME was compared), a veteran aged 70 was 1.04 times more likely to receive a manual wheelchair than a veteran aged 60 . Similarly, a veteran aged 60 was 1.04 times more likely to receive a power wheelchair or scooter than a veteran aged 70. When adjusted ORs for manual wheelchairs were compared, for every 10-year increase in age, a veteran was 1.08 times more likely to receive a standard wheelchair (type M1) and 1.04 times more likely to receive a lightweight rehabilitation wheelchair (type M2). For every 10-year decrease in age, a veteran was 1.25 times more likely to receive an ultralightweight wheelchair (type M3).

Table 6.

Distribution (percent) of wheelchairs by type (manual/power wheelchairs and scooters) across diagnoses for fiscal years 1999-2001 combined.

\begin{tabular}{|c|c|c|c|c|c|c|c|c|c|c|}
\hline \multirow{2}{*}{$\begin{array}{c}\text { Confounding } \\
\text { Variable: } \\
\text { Diagnosis }\end{array}$} & \multicolumn{10}{|c|}{ Dependent Variable: Wheelchair Type } \\
\hline & M1 & M2 & M3 & M4 & $\begin{array}{c}\text { Total } \\
\text { Manual }\end{array}$ & $\mathbf{P 1}$ & $\mathbf{P} 2$ & P3 & $\begin{array}{c}\text { Total } \\
\text { Power }\end{array}$ & $\begin{array}{c}\text { Total } \\
\text { Scooter }\end{array}$ \\
\hline ALS & $37^{*}$ & 13 & 2 & 8 & 60 & 8 & 9 & 6 & 40 & $16^{\dagger}$ \\
\hline SCIT & $23^{*}$ & $15^{\dagger}$ & 13 & 11 & 62 & 13 & 7 & 12 & 38 & 6 \\
\hline SCIP & $28^{*}$ & $20^{\dagger}$ & 13 & 11 & 73 & 7 & 5 & 5 & 27 & 10 \\
\hline $\mathrm{PD}$ & $59^{*}$ & $20^{\dagger}$ & 2 & 5 & 86 & 2 & 2 & 1 & 14 & 9 \\
\hline Amputation & $48^{*}$ & $19^{\dagger}$ & 3 & 7 & 78 & 4 & 3 & 2 & 22 & 13 \\
\hline COPD/CHF & $52^{*}$ & 14 & 1 & 6 & 73 & 3 & 2 & 1 & 27 & $21^{\dagger}$ \\
\hline Arthritis & $54^{*}$ & 15 & 1 & 7 & 78 & 3 & 2 & 1 & 22 & $16^{\dagger}$ \\
\hline
\end{tabular}


Table 7.

Regression results for manual (dependent variable) versus power wheelchairs for fiscal years (FYs) 1999-2001 combined ( $n=62,377)$. Results reported for veterans according to age, sex, and race/ethnicity.

\begin{tabular}{|c|c|c|c|}
\hline Independent Variable & Odds Ratio & $\begin{array}{l}\text { 95\% Confidence } \\
\text { Interval }\end{array}$ & $p$-Value \\
\hline Age & 1.003 & 1.002 to 1.005 & $<0.001^{*}$ \\
\hline Sex: Male & 1.061 & 0.961 to 1.171 & 0.24 \\
\hline Hispanic vs Caucasian & 1.864 & 1.682 to 2.067 & $<0.001^{*}$ \\
\hline American Indian/Asian vs Caucasian & 1.585 & 1.247 to 2.015 & $0.002^{*}$ \\
\hline African American vs Caucasian & 1.360 & 1.285 to 1.440 & $<0.001^{*}$ \\
\hline
\end{tabular}

Table 8.

Regression results for power wheelchairs (dependent variable) versus scooters for fiscal years (FYs) 1999-2001 combined ( $n=14,816$ ). Results reported for veterans according to age, sex, and race/ethnicity.

\begin{tabular}{lccc}
\multicolumn{1}{c}{ Independent Variable } & Odds Ratio & $\begin{array}{c}\text { 95\% Confidence } \\
\text { Interval }\end{array}$ & p-Value \\
\hline Age & 1.000 & 0.997 to 1.003 & 0.89 \\
Sex: Male & 0.936 & 0.784 to 1.118 & 0.47 \\
Race/Ethnicity & & & \\
Hispanic vs Caucasian & 1.850 & 1.518 to 2.254 & $<0.001^{*}$ \\
American Indian/Asian vs Caucasian & 1.928 & 1.190 to 3.124 & $0.008^{*}$ \\
$\quad$ African American vs Caucasian & 1.256 & 1.129 to 1.397 & $<0.001^{*}$ \\
\hline Note: Analysis was controlled for diagnosis, number of comorbidities, FY. & & & \\
* Significant at 0.05, confidence interval does not include 1. & & \\
\hline \hline
\end{tabular}

\section{Race/Ethnicity}

When all WME was compared (Table 7), Hispanics $(\mathrm{OR}=1.864)$, American Indians/Asians $(\mathrm{OR}=1.585)$, and African Americans (OR $=1.360$ ) were more likely than Caucasians to receive manual wheelchairs. Hispanics $(\mathrm{OR}=0.8)$ and African Americans $(\mathrm{OR}=0.9)$ were less likely than Caucasians to receive power wheelchairs, and Hispanics $(\mathrm{OR}=0.4)$, American Indians/Asians $(\mathrm{OR}=$ 0.4 ), and African Americans ( $\mathrm{OR}=0.7$ ) were less likely than Caucasians to receive scooters (data not shown).

When power wheelchairs and scooters were included in the analysis (manual wheelchairs excluded) (Table 8), minorities were more likely than Caucasians to receive power wheelchairs (Hispanics: OR $=1.850$, American Indians/Asians: $\mathrm{OR}=1.928$, and African Americans: $\mathrm{OR}=$ 1.256) and less likely to receive scooters (Hispanics: $\mathrm{OR}=$ 0.5, American Indians/Asians: $\mathrm{OR}=0.5$, and African Americans: $\mathrm{OR}=0.8$ ) (data not shown).

\section{DISCUSSION}

Demographic and clinical factors related to WME provision by the VHA were examined (1) to characterize veterans who received WME (by age, sex, race/ethnicity, diagnosis, number of comorbidities, and priority group) and (2) to determine whether a significant relationship existed between type of wheelchair and age, sex, or race/ ethnicity (when analysis was controlled for diagnosis and number of comorbidities).

During the 3-year study period, more than 191,000 wheelchairs and scooters were provided by the VHA, with a 14 percent increase in number of veterans who received WME from the VA between FY1999 and FY2001 (Table 2). Since the mean age of veterans who received WME changed by less than 1 year from FY1999 to FY2001, this increase is more likely attributed to the increased number of veterans provided healthcare by the VHA. According to VHA Allocation Resource Center data, between FY1999 and FY2001, the unique number of veterans who received complex care (e.g., for SCI or stroke) from the VHA increased by 10 percent. One explanation for this increased services use is the change in enrollment policy. Although this change was mandated by the U.S. Congress in 1998, it has taken years to implement. Interestingly, while the number of manual and power wheelchairs provided 
increased, the number of scooters provided decreased (Table 3). Similarly, the proportion of manual wheelchairs and scooters provided decreased, while the proportion of power wheelchairs increased. The increased provision of power wheelchairs is likely related to advances in technology, e.g., multiterrain devices.

For the purpose of this study, wheelchairs and scooters were categorized into eight types based on function, weight, and adjustability. Most studies comparing types of wheelchairs have focused on durability [28-31]. Only one other known study categorized wheelchairs to examine the relationship between customizability and demographic and socioeconomic factors; participants were 412 full-time wheelchair users with SCI [5]. The results of that study indicate that wheelchair provision patterns vary according to the type of wheelchair provided. Minorities were more likely to receive manual wheelchairs, and Caucasians more likely to receive power wheelchairs and scooters. Hunt et al. also found minorities were more likely than Caucasians to receive standard manual wheelchairs when only manual wheelchairs were considered, with no racial/ethnic differences for power wheelchairs [5].

\section{Race/Ethnicity}

In FY1999, 66 percent of veterans who received WME from the VHA and 73 percent of veterans who received healthcare from the VHA were Caucasian; 15 percent of veterans who received WME from the VHA and 15 percent of veterans who received healthcare from the VHA were African American; 5 percent of veterans who received WME from the VHA and 6 percent of veterans who received healthcare from the VHA were Hispanic (race/ethnicity data for veterans who received healthcare from the VHA could only be found in the FY1999 VHS) [20,25]. In comparison, according to the 2001 National Survey of Veterans [20,25], 63 percent of veterans who received WME from the VHA and 85 percent of the general veteran population were Caucasian; 13 percent of veterans who received WME from the VHA and 9 percent of the general veteran population were African American; and 5 percent of veterans who received WME from the VHA and 4.5 percent of the general veteran population were Hispanic.

The claim that minorities have an increased risk for injury in combat and increasingly more Hispanics are being assigned to frontline combat is not supported in the literature and thus does not explain the disproportionate representation just described. ${ }^{* \dagger \neq}$

Since the Vietnam war, African-American soldiers have opted for technical and communications positions that do not involve direct combat, i.e., positions that provide marketable skills upon discharge. ${ }^{* \S}$ In the 1991 Persian Gulf war, 17 percent of the fatalities were African Americans and 4.1 percent were Hispanic ${ }^{\S}$ at a time when the U.S. population was 18 percent African American and 4 percent Hispanic [28]. In the Iraq war, the frontline combat force is mostly Caucasian, ${ }^{\ddagger}$ although unfortunately, the noncombat support troops in Iraq have been unexpectedly subject to battle. ${ }^{\S}$

We conducted a secondary analysis to determine whether a higher proportion of ultralightweight manual wheelchairs were provided in regions with a higher Hispanic population, e.g., south Texas. However, we found this was not the case. Secondary analysis results revealed the highest proportion of ultralightweight wheelchairs was provided in the upstate New York area, which suggests regional differences need further and more detailed investigation. A description of regional differences will be published in a forthcoming paper that describes the VHA's costs in providing WME. In addition, a study examining variation at the facility level is currently underway.

Cultural preferences are an additional factor influencing provision of ATDs. For example, cultures with lower socioeconomic status may have smaller homes and larger extended families and a folding manual wheelchair may be preferred to a larger device, such as a power wheelchair or scooter. Public and private transportation of a power wheelchair or scooter may also be a problem, although the VA will frequently provide a lift that can be attached to the rear of an automobile. Further, we could hypothesize that some cultures may tend to rely more on

\footnotetext{
*Hoffman L, Hargrove T. Death has no bias among U.S. soldiers in Iraq. USA: CBS; 2004.

${ }^{\dagger}$ NewsMax.com. Black, Hispanic casualties not disproportionate.
2003 Jul 16 [cited 2004 July]. Available from:
http://www.newsmax.com/archives/articles/2003/7/15/161239.shtml
}

${ }^{\ddagger}$ Lacey JA. Minority war deaths: An ugly myth. The New York Post. 2002 Oct 14.

${ }^{\S}$ Hargrove T. Conflict with Iraq: Study shows 20 percent of war deaths are blacks. Naples Daily News. 2003 Apr 12. 
ATDs, while others rely on personal assistance. Minorities use personal assistance for disabilities 5 to 11 percent more than Caucasians [32] and the assistance is more likely to be informal versus paid [33]. Allen et al. found that wheelchair users were more likely to receive paid and nonpaid assistance than users of other types of ATDs; unfortunately analysis of assistance use by race/ ethnicity for wheelchair users was not reported [33]. Thus the question remains: To what extent does availability of personal assistance account for variability in manual versus power mobility prescription? This question is further compounded by cross-cultural variance in community participation by individuals with disabilities. Studies have found that the assumption that minorities have more informal care through extended families than Caucasians is false [34-35]: community-dwelling African Americans and Hispanics with disabilities were 38 percent more likely than Caucasians to have inadequate help [34]. The difference in these findings may be related to the measurement of "use of assistance" versus "adequacy of help.”

\section{Diagnosis}

Standard wheelchairs (type M1) were provided more than 50 percent of the time for veterans with stroke, TBI, PD, COPD/CHF, and arthritis. Standard wheelchairs may be appropriate for temporary use for conditions such as stroke and TBI. Garber et al. found that 31 percent of veteran participants who had had a stroke stopped using their manual wheelchairs, typically because of improved physical function or use of alternative devices such as walkers or canes [36]. Veterans with COPD/CHF and arthritis may be household ambulators but require a wheelchair for longer distances. Standard wheelchairs do, however, require more exertion and energy to propel $[13,37]$, which needs to be considered when wheelchairs are prescribed for veterans with deconditioning disorders such as COPD/CHF. Reissued lightweight rehabilitation or ultralightweight manual wheelchairs would be a costeffective solution for part-time wheelchair users and require less upper-limb exertion and overall endurance.

Veterans with SCI and some veterans with MS are more likely to rely on their wheelchairs for mobility. Veterans with SCI and MS received standard wheelchairs (type M1) less than 30 percent of the time: 28 percent of veterans with SCIP received standard manual wheelchairs from the VHA and 20 percent received customizable, ultralightweight wheelchairs (Table 6). However, some of the standard wheelchairs provided may have been spares. In contrast, Hunt et al. found that 97 percent of full-time wheelchair users with SCI who received their wheelchairs from SCI centers of excellence received customizable, ultralightweight wheelchairs [5]. The remaining 3 percent received manual wheelchairs that were not ultralightweight.

\section{Service Connection}

More than 50 percent of the more customizable manual and power wheelchairs were prescribed for nonservice-connected injuries. This finding may reflect the aging status of the World War II veterans who now require WME for non-service-connected conditions such as COPD/CHF and arthritis. Very few minority veterans fought in World War II and, therefore, the higher percentage of Caucasians who received scooters (mean age $\sim 67$ ) is not surprising.

Approximately 40 percent of veterans with SCI received standard power wheelchairs without programmable controls from the VHA, 26 percent received standard power wheelchairs with programmable controls, and 33 percent received customizable wheelchairs. In contrast, none of the power wheelchair users in the Hunt et al. study received a standard power wheelchair without programmable controls, 46 percent received standard power wheelchairs with programmable controls, and 54 percent received customizable wheelchairs [5]. Perhaps veterans with SCI are more likely to go to an SCI specialty-seating clinic for their wheelchairs. Hunt et al. found participants with customizable wheelchairs were more likely to have private health insurance ( $p=0.018)$ [5]. While specialtyseating clinics exist within the VHA, NPPD data does not document the clinic in which the wheelchair was prescribed, which is a limitation of the NPPD and this study.

Nearly 80 percent of the wheelchairs were prescribed for non-service-connected conditions. We should note that within the NPPD, a veteran can receive WME for a service-connected and a non-service-connected condition. For example, a veteran may receive an ultralightweight wheelchair for a service-connected injury (perhaps an SCI incurred while serving in Vietnam) and a scooter for a non-service-connected condition (e.g., $\mathrm{COPD} / \mathrm{CHF}$ as the veteran ages, with a lifestyle that perhaps includes smoking and little exercise).

Secondary analyses revealed a higher proportion of standard (37\% vs $26 \%$ ) and lightweight (24\% vs $19 \%)$ wheelchairs were provided for non-service-connected 
conditions than service-connected conditions ( $p \leq 0.001)$. A higher proportion of standard power wheelchairs ( $7 \%$ vs $4 \%$ ), custom power wheelchairs ( $5 \%$ vs $3 \%$ ), and scooters (22\% vs $17 \%)$ were provided for serviceconnected conditions than non-service-connected conditions $(p \leq 0.001)$. One limitation of this analysis is that it did not control for diagnosis. Diagnoses that resulted from a service-connected condition are likely to differ from those that resulted from a non-service-connected condition; i.e., a veteran is less likely to receive a wheelchair for a diagnosis of COPD or arthritis while on active duty.

\section{Age}

Younger veterans were more likely to receive ultralightweight wheelchairs. The mean age of veterans who received ultralightweight wheelchairs was $55 \pm 16$; these veterans are likely Vietnam veterans who may be more active, be more likely to compete in sports, and associate with peers who use sportier wheelchairs. The mean age of veterans who received standard manual wheelchairs was $67 \pm 13$; these veterans most likely served in the Korean or Vietnam wars. If veterans in their mid-to-late 60s are perceived as less active, they may also be perceived as having less need for sportier wheelchairs. One problem with this logic is that standard wheelchairs are heavier and nonadjustable and, therefore, increase the demands upon already arthritic joints for propulsion. The lighter the wheelchair, the easier it is to push. Wheelchair propulsion requires the upper limbs to produce repeated, forceful movements, which can result in carpal tunnel syndrome and injury to the shoulder [3843]. Lighter wheelchairs reduce the propulsion workload and thus lower the risk of secondary injuries to the user's arms and shoulders [37,44-46]. In addition, the heavier standard wheelchairs are difficult for aging caregivers to load into a car. When World War II veterans were injured, standard wheelchairs (patented in 1937) were the only available wheelchair design. Although standard wheelchairs were the most frequently prescribed wheelchairs, lightweight rehabilitation wheelchairs were also provided to older veterans (mean age 65.5 years). While rehabilitation wheelchairs are lighter, they do not provide the axle-position adjustability that reduces the repetitive stress generated during propulsion [10].

The mean age of veterans who received WME from the VHA during FYs 1999-2001 was $67 \pm 13$, 9 years older than the general veteran population (mean age $=58$ ) [25]. The mean ages of wheelchair users in the veteran and general U.S. populations were similar, 67 and $<65$ years, respectively [1,3].

\section{Limitations}

A limitation of studies that use administrative databases, which "are the by-product of running a healthcare system" [47], is that they do not provide information unique to each veteran, e.g., a description of their mobility, activity, and participation needs and functional levels. Because functional level data were not available, the distinction between type of wheelchair and functional level could not be made. For example, a veteran with a mild stroke will have different mobility needs than a veteran with a more massive brain-stem stroke. A second limitation of using this administrative database was that no information was available on the circumstances under which the devices were prescribed, i.e., the clinical environment and training and expertise of the clinician. However, veteran and system factors are included in a subsequent VA funded study.

Limitations were also posed by the NPPD data itself. In FY1999, 60,116 wheelchairs and scooters were provided by the VHA to 52,309 veterans. If a one-to-one correspondence between WME and individuals receiving the devices is assumed, there were 7,803 more wheelchairs and scooters provided than there were veterans to receive them. This result suggests that some veterans received more than one wheelchair during a FY, which is in accordance with the VHA Handbook. In fact, 1 percent of the wheelchairs provided were coded as spares, which would account for as many as 6,000 of the 7,803 wheelchairs and scooters. Coding variation may also explain the difference between the number of pieces of WME provided and number of veterans who received them. Wheelchair components were inconsistently coded as wheelchairs, perhaps in an effort to associate the component with the wheelchair it accompanied. Another factor was coding error.

Although the NPPD did provide an HCPCS code, no information on the make or model of the wheelchair was provided, which would have assisted in validating some of the other NPPD fields; i.e., having a brand name, model number, and HCPCS code could help differentiate inconsistencies in coding procedures across facilities and data entry persons within facilities and identify coding error. The capability to differentiate whether a wheelchair was purchased from a vendor or from a manufacturer 
would also have been helpful. The vendor field did not make this distinction clear.

While inquiring about the data entry process at the facility level, we discovered that the potential for discrepancies between prescription and provision practices existed. For example, a clinician prescribes a wheelchair. The prescription is then given to a vendor. The vendor purchase order is entered into the VA system and the device is delivered to the veteran's home (if outpatient). Apparently, no check is built into the system to ensure that the vendor has ordered what the clinician prescribed; thus, prescription should not be used interchangeably with provision.

While inquiring among wheelchair vendors with assistive technology specialists (ATSs) certified by the Rehabilitation Engineering and Assistive Technology Society of North America, we found that the NPPD includes outdated HCPCS codes from the 1970s. Possibly the use of outdated codes could contribute to confusion between vendors and the VHA. Where these outdated "E" codes originated from was unclear: the vendor or the VHA, but ATS vendors interviewed by the investigators were unfamiliar with most of the "E" codes.

Tracking WME after delivery to veterans could be useful. Wheelchairs, especially power wheelchairs, are expensive and frequently take many months to be delivered. In the meantime, a veteran's condition can change or the veteran may die (e.g., a veteran with ALS). A wheelchair no longer beneficial to one veteran may benefit another and could eliminate the months of waiting. While the VHA does refurbish and reissue wheelchairs, this study found this process is not being well tracked by the NPPD. A database designed to track veterans and wheelchairs could improve the quality of care to veterans and save money.

\section{CONCLUSIONS}

This was the first large-scale study to look at the types of wheelchairs prescribed in the context of disability. The findings strongly suggested disparity in the provision of wheelchairs by the VHA and that the standard of care for the provision of WME within the VHA is not of the same quality as in other populations.

The results of this study indicate Caucasians were more likely than Hispanics and African Americans to receive power wheelchairs. Caucasians were more likely than minorities (Hispanics, African Americans, Asians, and American Indians) to receive scooters and less likely to receive standard wheelchairs. Site-level analyses need to be completed to further investigate these findings. In addition, within the veteran population, the most frequently prescribed wheelchair for all diagnoses was the standard manual wheelchair.

\section{ACKNOWLEDGMENTS}

This material is the result of work supported with resources and use of facilities at the VA Rehabilitation Research and Development Center of Excellence of Wheelchairs and Related Technology; the VA Center of Excellence for Health Equity, Research, and Promotion; the VA Pre-Doctoral Associated Health Rehabilitation Research Fellowship Program; and the University of Pittsburgh Provost Pre-Doctoral Fellowship Program.

The authors have declared that no competing interests exist.

\section{REFERENCES}

1. Russell JN, Hendershot GE, LeClere F, Howie LJ, Adler M. Trends and differential use of assistive technology devices: United States, 1994. In: Advance data from vital and health statistics: No. 292. Hyattsville (MD): National Center for Health Statistics. 1997.

2. Rubin RM, White-Means SI. Race, disability and assistive devices: Sociodemographics or discrimination. Int J Soc Econ. 2001;28(10/12):927-41.

3. Kaye HS, Kang T, Laplante MP. Mobility device use in the United States. Report 14. Washington (DC): National Institute on Disability and Rehabilitation Research; 2000.

4. Tomita MR, Mann WC, Fraas LF, Burns LL. Racial differences of frail elders in assistive technology. Assist Technol. 1997;9(2):140-51. [PMID: 10177451]

5. Hunt PC, Boninger ML, Cooper RA, Zafonte RD, Fitzgerald SG, Schmeler MR. Demographic and socioeconomic factors associated with disparity in wheelchair customizability among individuals with traumatic spinal cord injury. Arch Phys Med Rehabil. 2004;85(11):1859-64. [PMID: 15520982]

6. Zimmer Z, Chappell NL. Mobility restriction and the use of devices among seniors. J Aging Health. 1994;6(2):185-208.

7. Hoenig H, Landerman LR, Shipp KM, George L. Activity restriction among wheelchair users. J Am Geriatr Soc. 2003;51(9):1244-51. [PMID: 12919236]

8. Cooper RA, Boninger ML, Cooper R, Thorman T. Wheelchair and seating. In: Lin VW, Cardenas DD, Cutter NC, 
Frost FS, Hammond MC, Lindbloom LB, Perkash I, Waters R, Woolsey RM, editors. Spinal cord medicine: Principles and practice. New York (NY): Demos; 2002. p. 635-54.

9. Cooper RA. Intelligent control of power wheelchairs. IEEE Eng Med Biol. 1995;4(14):423-31.

10. Cooper RA. Wheelchair selection and configuration. New York (NY): Demos; 1998. p. 1-19.

11. Kwarciak AM, Cooper RA, Ammer WA, Fitzgerald SG, Boninger ML, Cooper R. Fatigue testing of selected suspension manual wheelchairs using ANSI/RESNA standards. Arch Phys Med Rehabil. 2005;86(1):123-29. [PMID: 15641002]

12. Rentschler AJ, Cooper RA, Fitzgerald SG, Boninger ML, Guo S, Ammer WA, Vitek M, Algood D. Evaluation of selected electric-powered wheelchairs using the ANSI/ RESNA standards. Arch Phys Med Rehabil. 2004;85(4): 611-19. [PMID: 15083438

13. Cooper RA. A perspective on the ultralight wheelchair revolution. Technol Disabil. 1996;5:383-92.

14. Cooper RA, Fitzgerald SG, Boninger ML, Prins K, Rentschler AJ, Arva J, O’Connor RJ. Evaluation of a pushrimactivated, power-assisted wheelchair. Arch Phys Med Rehabil. 2001;82(5):702-8. [PMID: 11346854]

15. Cohen LJ, Fitzgerald SG, Lane S, Boninger ML. Development of the seating and mobility script concordance test for spinal cord injury: Obtaining content validity evidence. Assist Technol. 2005;17(2):122-32. [PMID: 16392716]

16. Cooper R, Boninger ML, Brienza D, Van Roosmalen L, Koontz A, LoPresti E, Spaeth D, Bertocci G, Guo S, Buning $M$, Schmeler $M$, Geyer M, Fitzgerald SG, Ding D. Pittsburgh wheelchair and seating biomechanics research program. J Soc Biomech. 2003;27(3):144-57.

17. Rainer J. Seating assessment/prescription in a rural area. 20th International Seating Symposium; 2004 Mar 2-4; Vancouver, British Columbia, Canada. Vancouver, British Columbia (Canada): University of British Columbia Interprofessional Continuing Education; 2004. p. 237-38.

18. Issacson M. Best practices of OT \& PT performing seating and mobility evaluations. 20th International Seating Symposium; 2004 Mar 2-4; Vancouver, British Columbia, Canada. Vancouver, British Columbia (Canada): University of British Columbia Interprofessional Continuing Education; 2004. p. 241-42.

19. Battista RN. Innovation and diffusion of health-related technologies. A conceptual framework. Int J Technol Assess Health Care. 1989;5(2):227-48. [PMID: 10303488]

20. VIReC. The researcher's guide to VA data [homepage on the Internet]. Washington (DC): Department of Veterans Affairs; c2006 [updated 2006 Oct 16; cited 2002 Sep 30]. Available from: http://www.virec.research.med.va.gov

21. Fitzgerald SG, Reker D. Assessment of the National Prosthetics Patient Database: Preliminary studies of validity.
Pittsburgh (PA): Department of Veterans Affairs Rehabilitation Research and Development; 2003.

22. World Health Organization. WHO family of international classifications [homepage on the Internet]. Geneva (Switzerland): World Health Organization; c2006 [updated 2006 Nov 7; cited 2004 Mar 29]. Available from:

http://www.who.int/classification/

23. Kazis LE, Miller DR, Skinner KM, Lee A, Rex XS, Clark JA, Rogers WH, Spiro A 3rd, Selim A, Linzev M, Payne SM, Mansell D, Fincke RG. Patient reported measures of health: The Veterans Health Study. J Ambul Care Manage. 2004;27(1):70-83. [PMID: 14717468]

24. Office of Quality and Performance, Veterans Health Administration. Health status and outcomes of veterans: Physical and mental component summary scores, Veterans SF-36, 1999 National VHA Health Survey of Veteran Enrollees, Executive Report. Washington (DC): Department of Veteran Affairs, Veterans Health Administration, Office of Quality and Performance; 2000.

25. Department of Veterans Affairs. Program Statistics. [homepage on the internet]. Washington (DC): Department of Veterans Affairs; c2006 [updated 2006 Jul 7; cited 2002 October 21]. Available from: http://www.va.gov/vetdata/

26. Huck SW. Reading statistics and research. 3rd ed. New York (NY): Longman; 2000. p. 590-605.

27. Munro B. Statistical methods for health care research. 4th ed. Philadelphia (PA): Lippincott Williams and Wilkins; 2001. p. 283-99.

28. Fitzgerald SG, Cooper RA, Boninger ML, Rentschler AJ. Comparison of fatigue life for 3 types of manual wheelchairs. Arch Phys Med Rehabil. 2001;82(10):1484-88. [PMID: 11588758]

29. Cooper RA, Gonzales J, Lawrence B, Rentschler A, Boninger ML, VanSickle DP. Performance of selected lightweight wheelchairs on ANSI/RESNA tests. Arch Phys Med Rehabil. 1997;78(10):1138-44. [PMID: 9339166]

30. Rogers H, Berman S, Fails D, Jaser J. A comparison of functional mobility in standard vs ultralight wheelchairs as measured by performance on a community obstacle course. Disabil Rehabil. 2003;25(19):1083-88. [PMID: 12944147]

31. Hastings JD, Fanucchi ER, Burns SP. Wheelchair configuration and postural alignment in persons with spinal cord injury. Arch Phys Med Rehabil. 2003;84(4):528-34. [PMID: 12690591]

32. Verbrugge LM, Sevak P. Use, type, and efficacy of assistance for disability. J Gerontol B Psychol Sci Soc Sci. 2002; 57(6):S366-79. [PMID: 12426445]

33. Allen SM, Foster A, Berg K. Receiving help at home: The interplay of human and technological assistance. J Gerontol B Psychol Sci Soc Sci. 2001;56(6):S374-82. [PMID: 11682598] 
34. Lima JC, Allen SM. Targeting risk for unmet need: Not enough help versus no help at all. J Gerontol B Psychol Sci Soc Sci. 2001;56(5):S302-10. [PMID: 11522812]

35. Roschelle AR. No more kin: Exploring race, class, and gender in family networks. Thousand Oaks (CA): Sage Publications; 1997. p. 156.

36. Garber SL, Bunzel R, Monga TN. Wheelchair utilization and satisfaction following cerebral vascular accident. J Rehabil Res Dev. 2002;39(4):521-34.

37. Boninger ML, Souza AL, Cooper RA, Fitzgerald SG, Koontz AM, Fay BT. Propulsion patterns and pushrim biomechanics in manual wheelchair propulsion. Arch Phys Med Rehabil. 2002;83(5):718-23. [PMID: 11994814$]$

38. Gellman H, Sie I, Waters RL. Late complications of the weight-bearing upper extremity in the paraplegic patient. Clin Orthop Relat Res. 1988;(233):132-35. [PMID: 3402118]

39. Bayley JC, Cochran TP, Sledge CB. The weight-bearing shoulder. The impingement syndrome in paraplegics. J Bone Joint Surg Am. 1987;69(5):676-78. [PMID: 3597466]

40. Kulig K, Newsam CJ, Mulroy SJ, Rao S, Gronley JK, Bontrager EL, Perry J. The effect of level of spinal cord injury on shoulder joint kinetics during manual wheelchair propulsion. Clin Biomech (Bristol, Avon). 2001;16(9):744-51. [PMID: 11714551]

41. Boninger ML, Towers JD, Cooper RA, Dicianno BE, Munin MC. Shoulder imaging abnormalities in individuals with paraplegia. J Rehabil Res Dev. 2001;38(4):401-8. [PMID: 11563493]
42. Goodman CM, Steadman AK, Meade RA, Bodenheimer C, Thornby J, Netscher DT. Comparison of carpal canal pressure in paraplegic and nonparaplegic subjects: Clinical implications. Plast Reconstr Surg. 2001;107(6):1464-71. [PMID: 11335819]

43. Robertson RN, Boninger ML, Cooper RA, Shimada SD. Pushrim forces and joint kinetics during wheelchair propulsion. Arch Phys Med Rehabil. 1996;77(9):856-64. [PMID: 8822674]

44. Boninger ML, Baldwin M, Cooper RA, Koontz A, Chan L. Manual wheelchair pushrim biomechanics and axle position. Arch Phys Med Rehabil. 2002;81(5):608-13. [PMID: 10807100]

45. Koontz AM, Cooper RA, Boninger ML. An autoregressive modeling approach to analyzing wheelchair propulsion forces. Med Eng Phys. 2001;23(4):285-91.[PMID: 11427366]

46. Van der Woude LH, Veeger HE, Dallmeijer AJ, Janssen TW, Rozendaal LA. Biomechanics and physiology in active wheelchair propulsion. Med Eng Phys. 2001;23(10): 713-33. [PMID: 11801413]

47. Iezzoni LI. Using administrative data to study persons with disabilities. Millbank Q. 2002;80(2):347-79.

[PMID: 12101876]

Submitted for publication November 22, 2005. Accepted in revised form April 11, 2006. 